\title{
Microballoons: A Gastro Retentive Drug Delivery System
}

\author{
Ankita Srivastava*, Ruchi Shukla, Kusum Sharma, Hitesh Jain, D. B. Meshram
}

Pioneer Pharmacy Degree College, Vadodara, Gujarat, 390019, India

\begin{abstract}
Oral route is most preferable and widely used route for the administration of drug. Microballoons becomes novel technology in pharmaceutical field in the floating drug delivery for achieving the gastric retention. Microballoons are also called as hollowspheres which are porous smooth in nature and thus show good floating properties in gastric fluid. Microballoons release the drug in controlled manner at the targeted site. Microballoons are spherical empty vesicles without core and that can remain buoyant in gastric region for prolong period of time without irritation in gastrointestinal tract. Multiparticulate particles having a low density system that can efficiently prolong the gastric retention time of the drugs, thus enhanced bioavailability and thus improve the dosing frequency. These are less soluble at higher pH environment. As microballoons delivery systems provide longer retention in gastric $\mathrm{pH}$ and enhance the solubility of drugs that are less soluble in high $\mathrm{pH}$ environment. The formation of cavity inside the microballoons depend on the preparation, temperature and the surface smoothness determine the floatability and the release rate of microballoons.
\end{abstract}

Keywords: Microballoons, Gastro retentive drug delivery system, Hollowspheres, Controlled release

Article Info: Received 17 June 2019; $\quad$ Review Completed 20 July 2019; $\quad$ Accepted 23 July $2019 ; \quad$ Available online 15 August 2019

\section{Cite this article as:}

Srivastava A, Shukla R, Sharma K, Jain H, Meshram DB, Microballoons: A Gastro Retentive Drug Delivery System, Journal of Drug Delivery and Therapeutics. 2019; 9(4-s):625-630 http://dx.doi.org/10.22270/jddt.v9i4-s.3274

*Address for Correspondence:

Ankita Srivastava, Pioneer Pharmacy Degree College, Vadodara, Gujarat, 390019, India

\section{Introduction}

Microballoons are the gastro retentive drug delivery system and it is based on the non-effervescent approach. Generally microballoons are in spherical shape without core. These microballoons are free flowing powder which consists of protein and synthetic polymers and these microballoons size ranges from $200 \mu \mathrm{m}$. These microballoons are low density system which have sufficient buoyancy to float over the gastric fluid for prolonged period of time without any irritation to gastro intestinal tract. ${ }^{1}$ Microballoons are prepared by using different techniques such as simple solvent evaporation method, double emulsion method, phase separation coacervation method, polymerization method, spray drying method, spray congealing method and hot melt encapsulation method. ${ }^{2}$

\section{Advantages}

- Improves patient compliance by decreasing dosing frequency.

- Gastric retention time is increased.
- $\quad$ Plasma drug concentration is maintained.

- Controlled release of drug for prolonged period of time.

- $\quad$ Site-specific drug delivery to stomach can be achieved.

- $\quad$ No risk of dose dumping.

- Enhanced absorption of drug which solubilize only in stomach. 3,4

\section{Mechanism of drug release}

When microballoons comes in the contact with the gastric fluid the gel formers, polysaccharides and the polymers will hydrate to form colloidal gel barriers that controls the rate of fluid penetration in the device and the drug will release in controlled manner. The surface of the drug dissolves the gel layer is maintained by the hydration. The air trapped by swollen polymers which lowers the density and confers buoyancy to the microballoons.., 6 


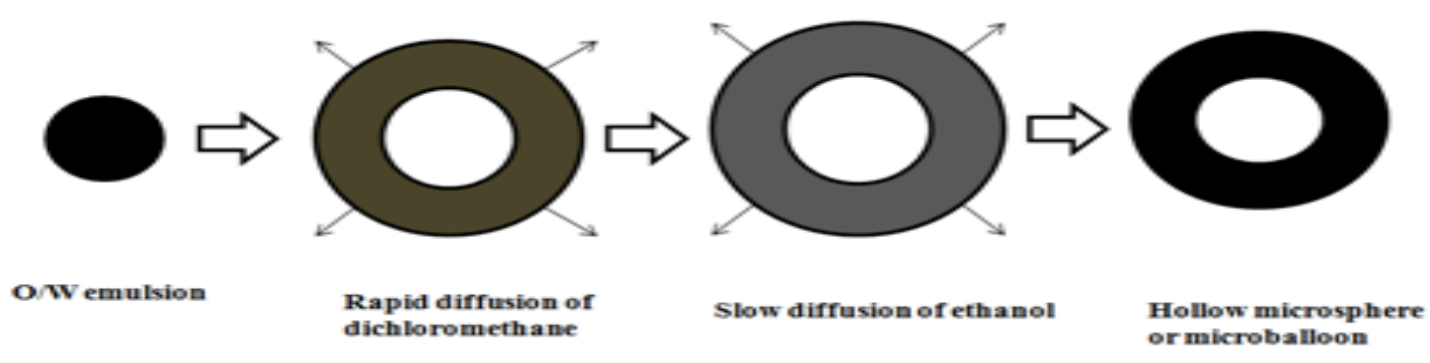

Figure 1: Microballoons

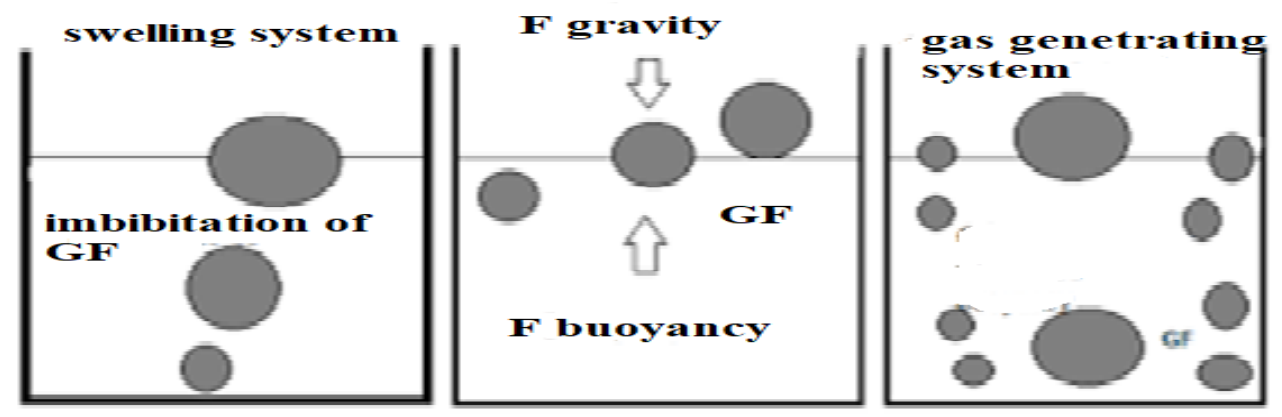

Figure 2: Mechanism of drug release

\section{Formulation method}

1. Emulsion Solvent Evaporation Method

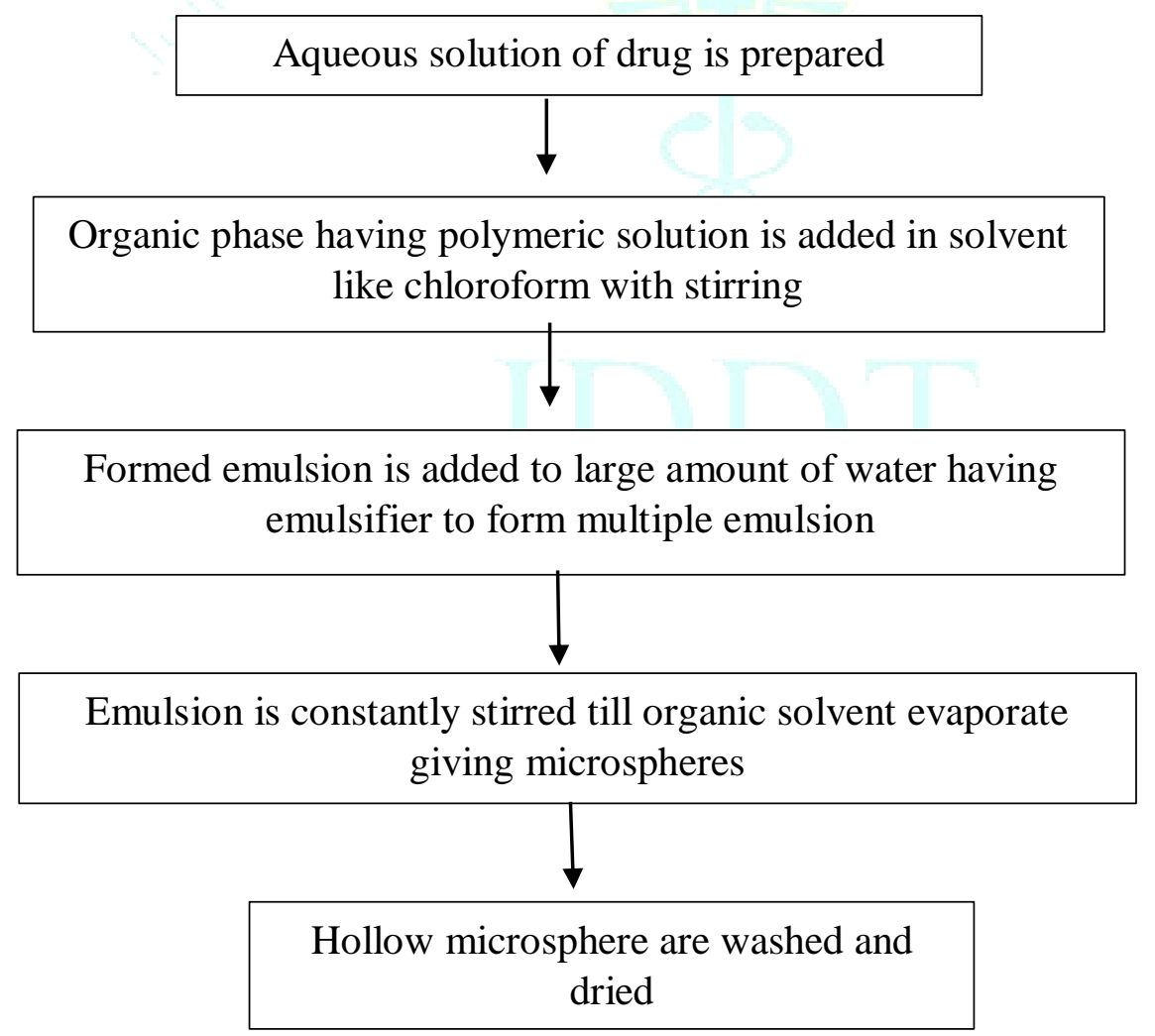

Figure 3: Emulsion solvent evaporation $\operatorname{method}^{7}$ 


\section{Emulsion Solvent Diffusion Method}

In this method solution of polymer and drug in ethanol methylene chloride is poured into an agitated aqueous solution of poly vinyl alcohol the ethanol rapidly partition into the external aqueous phase and the polymer precipitate around methylene chlorine droplets. The evaporation of entrapped methylene chloride leads to the formation internal cavities within the micro particles. 8,9

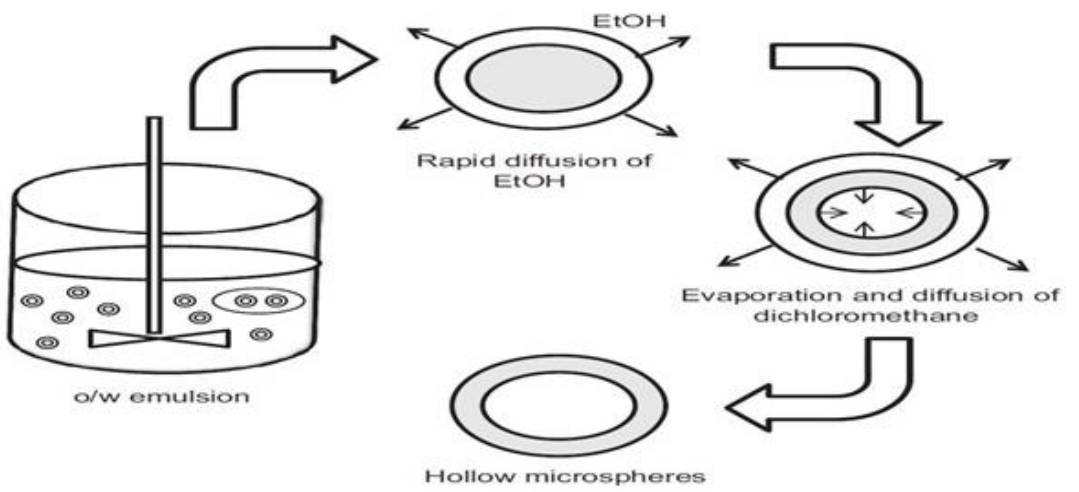

Figure 4: Emulsion solvent diffusion method

\section{Single emulsion technique}
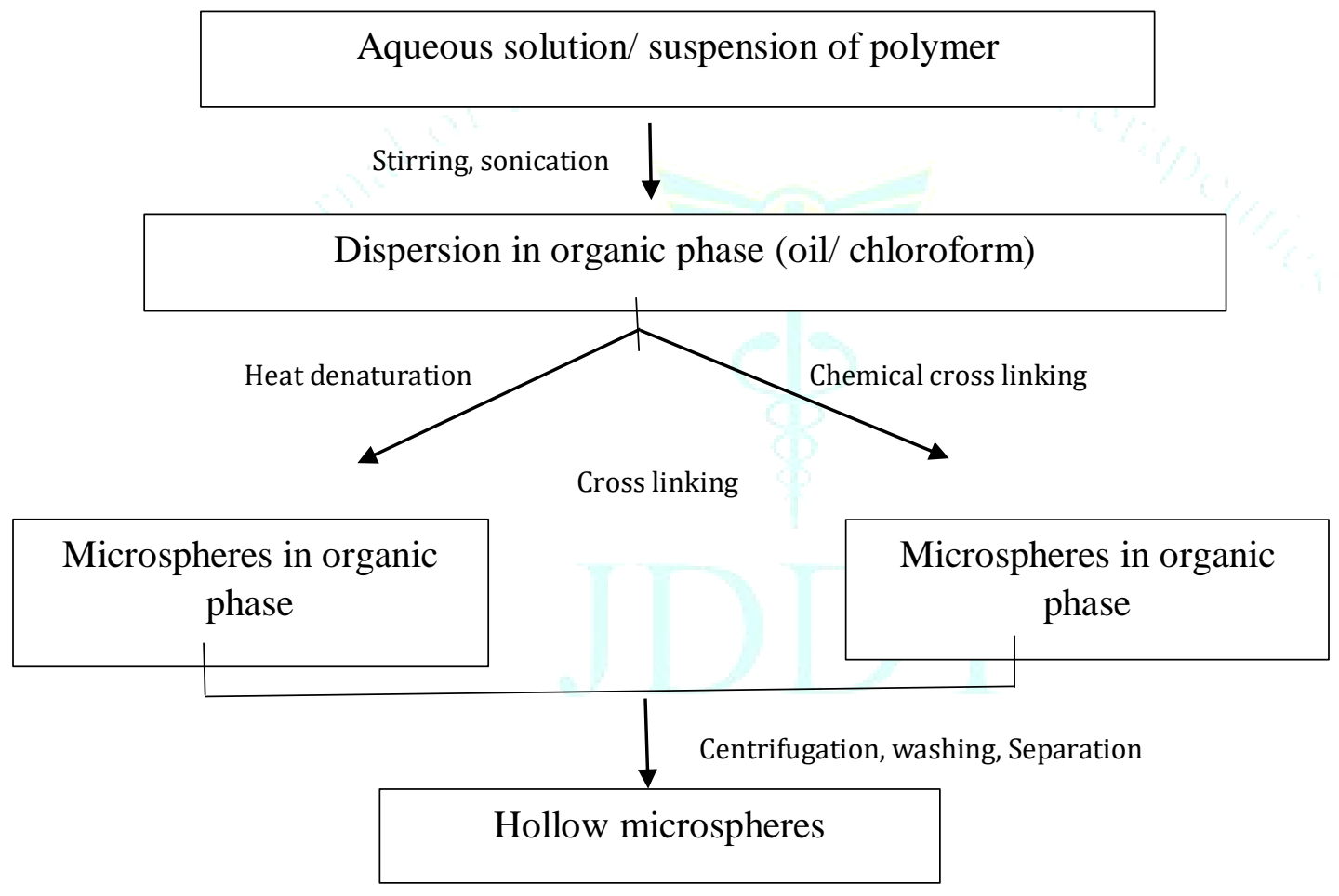

Figure 5: Single emulsion technique ${ }^{10}$ 
4. Double emulsion technique

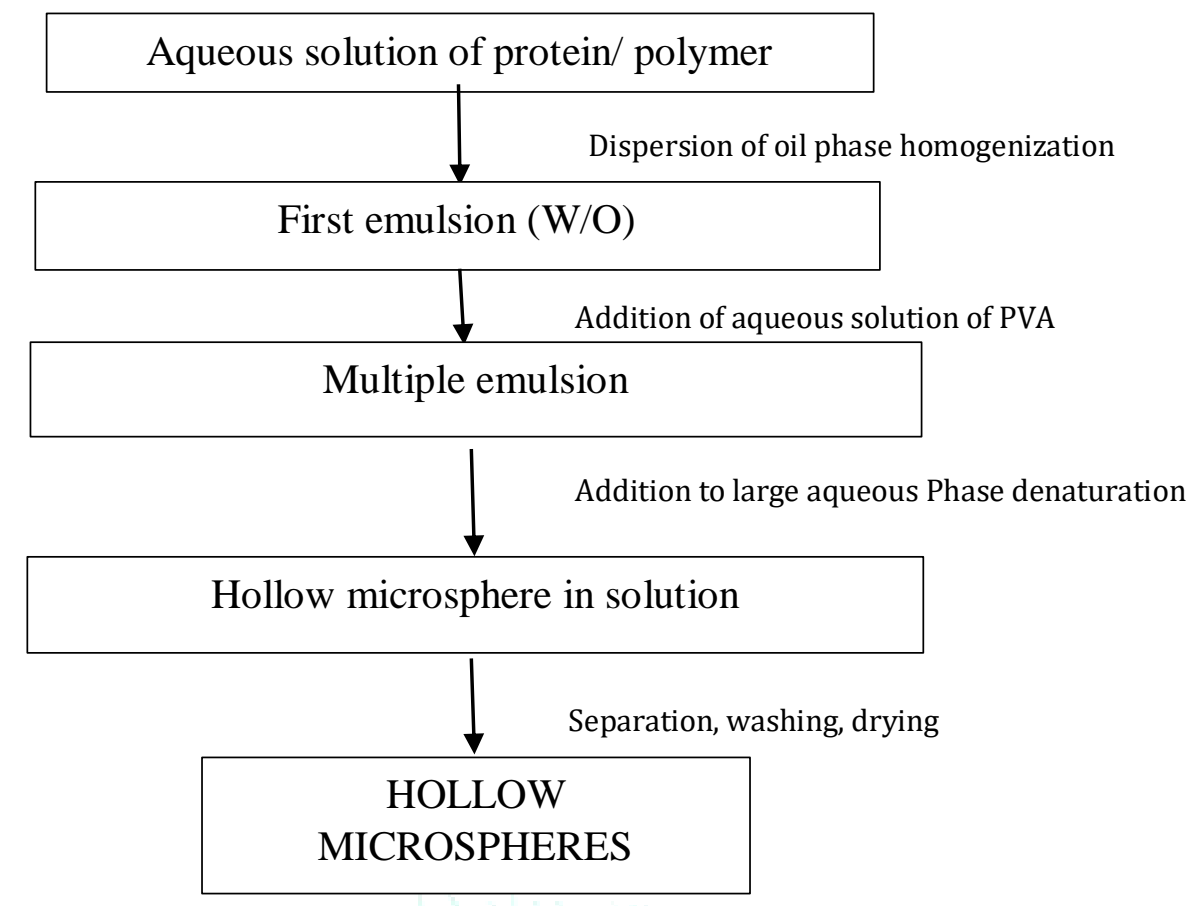

Figure 6: Double emulsion techniques11

\section{Coacervation phase separation technique}

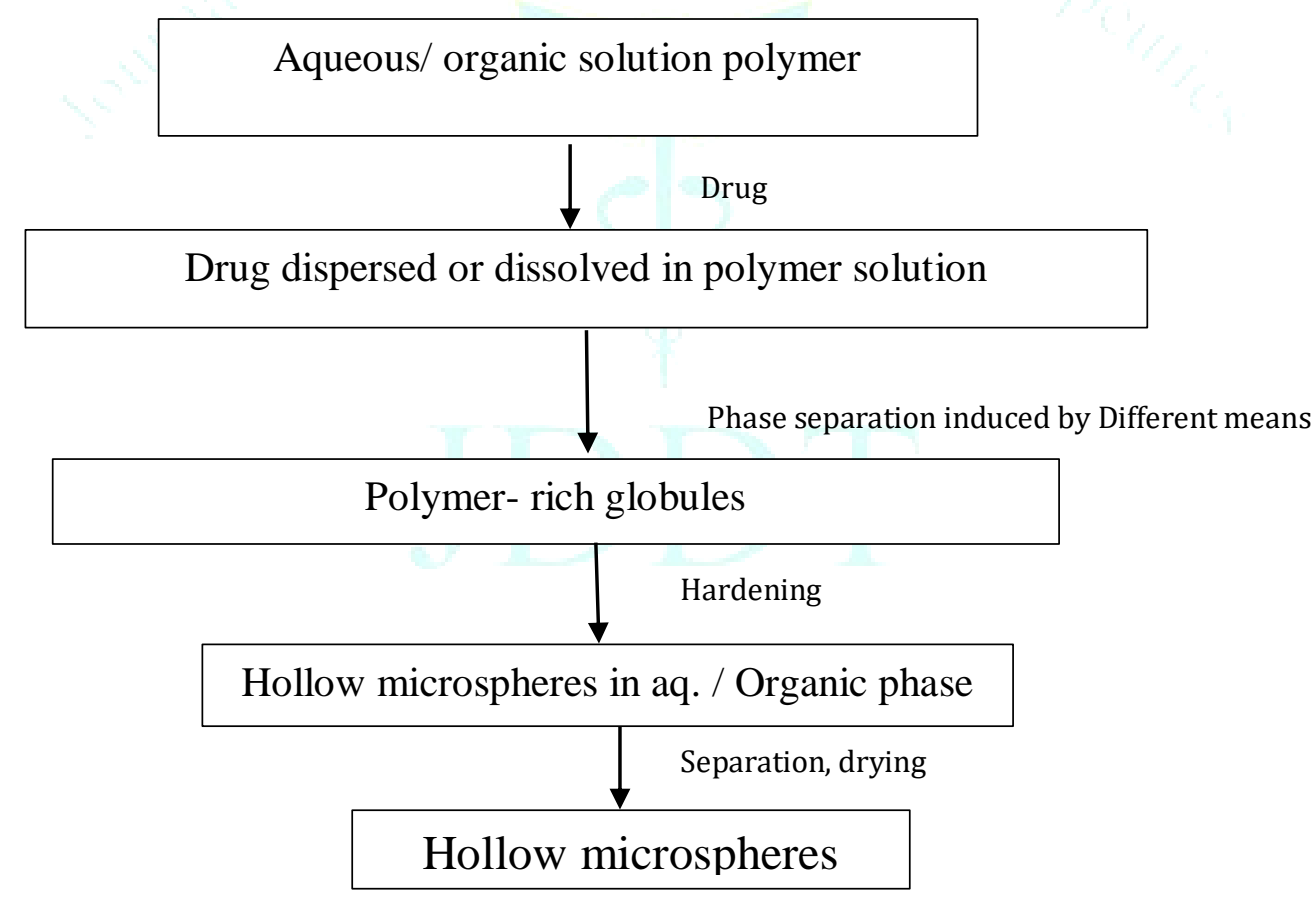

Figure 7: Coacervation phase separation method 12

\section{Spray drying and spray congealing}

Spray drying: - The coating solidification can be done by rapid evaporating of solvent in which coating material is dissolved.
Spray congealing: - The coating solidification can be done by thermally congealing a molten coating material. The removal of solvent is done by sorption, extraction or evaporation. ${ }^{13,14}$ 


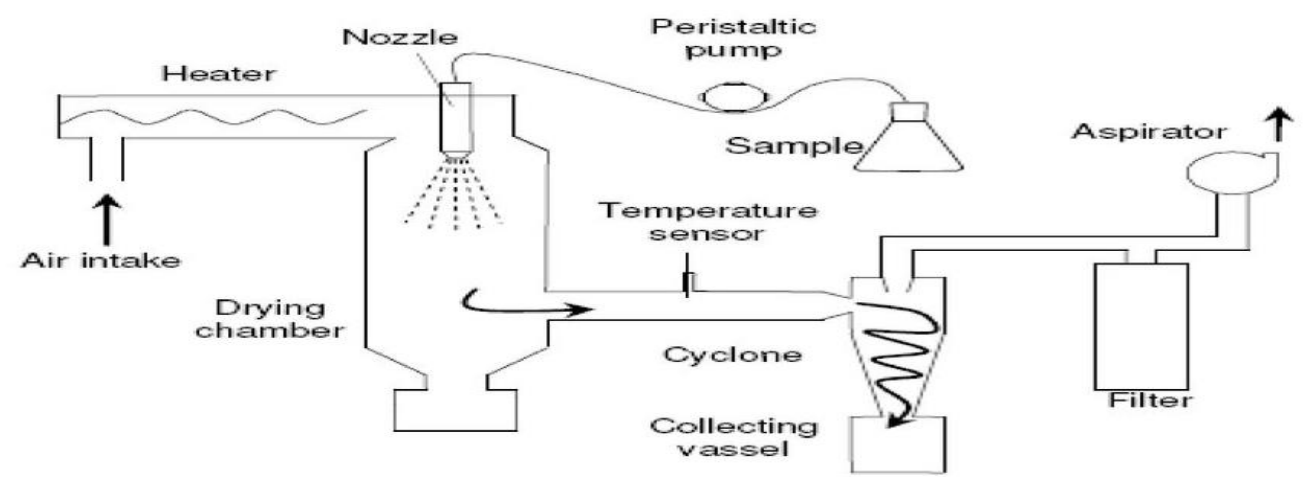

Figure 8: Spray drying and spray congealing

\section{Application of Microballoons}

- Gastro retentive floating microspheres are very effective in the reduction of major adverse effect of gastric irritation.

- $\quad$ Floating microballoons are very effective approach in delivery of drug that have poor bioavailability because of their limited absorption in the upper GIT.
- The higher dose of drug can reduced due to increase in gastric retention times which lead to low dose frequency.

- These system remain in stomach for long period of time and hence drug release in controlled manner. ${ }^{15-17}$

\section{Evaluations of Microballoons}

Microballoons can be evaluated for their micromeritic properties $^{18}$, particle size ${ }^{19}$, scanning electron microscopy ${ }^{20}$, Bulk density, Tapped density21, Carr's index, Angle of repose, Production yield 22 and In-vitro drug release 23 .

\section{Marketed formulations}

Table 1: List of marketed formulations of Microballoons

\begin{tabular}{|c|c|c|}
\hline Drug & Brand name & Manufacturer name \\
\hline Nizatidine & Tazac & Dr. Reddy Laboratories LTD. \\
\hline Propranolol Hydrochloride & Inderal & Nishchem International Pvt. Ltd \\
\hline Domperidone & Motilium & Kores India Limited \\
\hline Theophylline & Uniphyl & \\
\hline
\end{tabular}

\section{Conclusion}

Microballoons are low-density system and have sufficient buoyancy to float over gastric contents and remain in stomach for prolonged period without any irritation to gastro intestinal tract. The drug is released in controlled manner at desired rate when it floats over gastric fluid it resulting in the reduced fluctuations in plasma drug concentration. Hollow spheres promises to be a potential approach for the gastric retention. Optimized microballoons are novel drug delivery, particularly in diseased cell sorting, diagnostics, gene \& genetic materials, safe, targeted and effective in vivo delivery.

\section{References}

1. Patel S et.al, Microballoons: a novel approach in gastro-retention floating drug delivery system (FDDS), An International Journal of Pharmaceutical Science, 2016; 7(2): 332-345.

2. Vyas SP, Khar RK. Targeted and Controlled Drug Delivery Novel Carrier System. New delhi: CBS Publishers and Distributors; 2002. P. 417-454.

3. Arora S, Ali J, Ahuja A, Khar RK, Baboota S, Floating drug delivery systems: a review, Journal of American Association of Pharmaceutical Scientist, 2005; 6(3): 372-390.

4. Wu PC, Tsai MJ, Huang YB, Cheng JS, Tsai YH, In vitro and in vivo evaluation of potassium chloride sustained release formulation prepared with saturated polyglycolyed glycerides matrices, Int. J. Pharm, 2002; 119-124.
5. Yadav A, Kumar D, Gastroretentive microballoons of Metformin: Formulation Development and Characterization, J Adv Pharm Technol Res, 2011; 2(1): 51-55.

6. Senthil P, Senthil C, Abdul AH, Microballoons - from formulation to pharmaceutical design and applications, World Journal of Pharmacy and Pharmaceutical Sciences, 2016; 5(5): 341-352.

7. Somwanshi SB et.al, Floating Multiparticulate Oral Sustained Release Drug Delivery System, J Chem Pharm Res, 2011; 3(1): 536-547.

8. Azza AH, Marwa H, Gastro retentive Nizatidine Loading Microballoons for Treatment of Peptic Ulcer, International Journal of Pharmacy and Pharmaceutical Sciences, 2015; 7(10): 315-333.

9. Kumar DJ, Formulation and Evaluation of Gastro retentive floating microballoons of Anti diabetic drugs, Asian Journal of Pharmacy and Life Science, 2011; 1(2): 402-408.

10. Swami G, Saraf SA, Preparation and Evaluation of sustained release micro balloons of propranolol, Daru Journal of Pharmaceutical Sciences, 2011; 19(3): 502-507.

11. Joshi VK, Jaimini M, Microballons drug delivery system: A review, Asian Journal of Pharmaceutical Research and Development, 2013; 1(1): 7-17.

12. Saneshan GV, Kanth K, Preparation and in vitro evaluation of microballoon drug delivery system of Telmisartan, Int. J. Pharm. Sci. and Drug Res, 2013; 5(4): 141-145.

13. Sharma M, Kohli S, Dinda A, In vitro and in vivo evaluation of Repaglinide loaded floating microspheres prepared from different viscosity grades of HPMC polymer, Saudi Pharm J, 2015; 23: 675-682. 
14. Bansal H, Kaur SP, Gupta AK, Microspheres: Methods of preparation and applications: A comparative study, Int. J. Pharm. Sci. Rev. Res, 2011; 10: 69-78.

15. Deng $Y$ et al., Preparation, Characterization, and Application of Multistimuli-Responsive Microspheres with FluorescenceLabeled Magnetic Cores and Thermoresponsive Shells, Chem. Eur. J, 2005; 11(20): 6006-13.

16. Chaurasia H, Chaurasia D, Singh S, Formulation and In-Vitro Evaluation of Floating Microballoons of Indomethacin, Acta Poloniae Pharmaceutical Drug Research, 2010; 67(3): 291 - 298.

17. Dehghan MH, Khan FN, Gastroretentive Drug Delivery Systems: A Patent Perspective, Int J Health Res, 2009; 2(1): 23-44.

18. Gattani YS, Kawtikwar PS, Sakarkar DM, Formulation and evaluation of gastroretentive multiparticulate drug delivery system of aceclofenac, Int. J. Chem. Tech. Res, 2009; 1: 1-10.
19. Sarkar BS, Tanwar SS, Soni P, Jain P, Formulation, characterization and in vitro evaluation of floating microspheres of Esomeprazole, Int. J. of Bioassay, 2012; 21(2): 120-124.

20. Pusp RN, Myung KC, Hoo KC, Preparation of floating microspheres for fish farming, International Journal of Pharmaceutics, 2007; 341: 85-90.

21. Sato $Y$, Kawashima $Y$, Takeuchi $H$, Yamamoto $H$, In vitro evaluation of floating and drug releasing behaviors of hollow microspheres (microballoons) prepared by the emulsion solvent diffusion method, European Journal of Pharmaceutics and Biopharmaceutics, 2004; 57(2): 235-43.

22. Amrutha R, Lankapalli S, Suryadevara V, Formulation and evaluation of controlled release floating Microballoons of stavudine, Scientia Pharmaceutica, 2015; 83(4): 671-682.

23. Tripathi M, Formulation and evaluation of Glipizide hollow Microballoons for floating drug delivery, Bull. Pharm. Res, 2011; 1(1): 67-74. 